\title{
Research of Fresh Agricultural Products Transverse Replenishment and Deployment in Supermarket Chains*
}

\author{
Zilong Song \\ School of Logistics, Beijing Wuzi University, Beijing, China \\ Email: songzilong8@163.com
}

Received 6 June 2016; accepted 16 August 2016; published 19 August 2016

Copyright (C) 2016 by author and Scientific Research Publishing Inc.

This work is licensed under the Creative Commons Attribution International License (CC BY). http://creativecommons.org/licenses/by/4.0/

(c) (i) Open Access

\begin{abstract}
This paper looks into the flow and inventory status of the supermarket chains fresh agricultural products, then analyzes the traditional method for the surplus fresh agricultural products or the shortages and its limitations. Innovatively, all the affiliated stores of supermarket chains in this paper are regarded as a system, then the transverse replenishment and deployment method is proposed, and it is applied to the solution of the surplus fresh agricultural products or the shortages of the supermarket chains. To describe transverse replenishment method in detail, two sub models: inventory-total cost model and transportation model of transverse replenishment are established. MATLAB software is used to calculate and analyze the transverse replenishment model. The inventory-total cost model of the transverse replenishment proves the conclusion that the inventory total cost of the whole system is lower compared with the traditional replenishment method. The transportation model of the transverse replenishment gives the optimal dispatching scheme between the surplus supermarket and the shortages supermarket in order to minimize the total transportation costs. The transverse replenishment method in this paper is firstly applied to the fresh agricultural products of supermarket chains, and it can provide a new method for the supermarket chains to managed the inventory of fresh agricultural products so as to reduce total inventory costs of the whole the supermarket chains system, to maximize the overall system profits, and to improve the customer service levels as much as possible.
\end{abstract}

\section{Keywords}

Supermarket Chains, Fresh Agricultural Products, Transverse Replenishment, Inventory Total Cost Model, Transportation Model

\footnotetext{
*Key project of Philosophy and Social Science Research in Beijing (09AbJG299), key project of training plan of Beijing young top-notch talent (CIT\&TCD201304109), key projects of Innovation and Entrepreneurship of Beijing Wuzi University (0541605843).
} 


\section{Introduction}

As we all know, agricultural products are the most common and essential food in our daily life, which the safety and freshness are the first condition in the residents' consumption. With the economic and social development and the improvement of people's living standards, consumer demand for fresh agricultural products experienced the process of change from quantity to quality. People are in favor of more safety, environmentally protective, green, organic agricultural products. When consumers buy fresh agricultural products, fresh, green, organic, health products are taken into consideration. Usually, the main sources of the supply of fresh agricultural products include farmers' markets and supermarkets. Compared with farmers' markets and others, supermarkets are more secure in fresh quality and security. Unified procurement, processing, distribution and strict checks of various aspects let it meet the special requirements in the circulation with irreplaceable advantages. Therefore, supermarket chains become the primary place for consumers to buy fresh agricultural products. However, as more and more people choose to go to the supermarket chains to buy fresh agricultural products, the uncertainty of demand for fresh produce leads to the inaccurate forecasts of supermarket for fresh agricultural products demand. Thus, to a certain extent, this causes the stockpiles or shortages of fresh agricultural products of supermarket, affects the consumer demand for fresh agricultural products, and finally causes some damage of the supermarkets interests. Therefore, research of the transverse replenishment policy of supermarket chains fresh agricultural products can not only ensure the individual needs of consumers for fresh agricultural products, improve customer satisfaction, but also reduce the inventory costs and improve the profits of supermarket chains, make the supermarket chains healthy and fast organic development.

Up to now, researches about the fresh agricultural products transverse replenishment and deployment in supermarket chains are also less. Existing literatures has done some related researches about the shortage, surplus and replenishment of fresh agricultural products.

Wang Weixing (2006) [1] constructed a optimal ordering inventory model under multi-stage continuous demand for perishable products, and started to get the optimal total cost from global suppliers, manufacturers and retailers tripartite. Shui Wenbing, He Min and He Mingwei (2012) [2] developed a multi-product location-inventory model based on the coordinated replenishment multi-product inventory control policy. The minimum of the sum of location cost, transport cost and inventory cost was taken as the objective function of the model, and location number, service scope and inventory control parameters of distribution centers were chosen as the decision variables. Chaaben Kouki et al. (2015) [3] established inventory control model, which contributed to the literature by providing a simple and effective algorithm to compute the best $(r, Q)$ parameters that minimized the total cost. Yiyan Qin et al. (2014) [4] considered the pricing and lot-sizing problem for products with quality and physical quantity deteriorating simultaneously, and designed the optimal model to investigate the deterioration inventory of fresh produce and foods. Biswajit Sarkar and Sumon Sarkar (2013) [5] expanded an inventory model for deteriorating items with stock-dependent demand to determine the optimal cycle length of each product such that the expected total cost (holding, shortage, ordering, deterioration and opportunity cost) was minimized. Yu-Ping Leea and Chung-Yuan Dyeb (2012) [6] formulated a deteriorating inventory model with stockdependent demand by allowing preservation technology cost as a decision variable in conjunction with replacement policy to find the optimal replenishment and preservation technology investment strategies while maximizing the total profit per unit time. Joaquín Siciliaa et al. (2014) [7] studied a deterministic inventory system for items with a constant deterioration rate. They considered the ordering cost, the holding cost, the backlogging cost, the deteriorating cost, and the purchasing cost in the inventory management and proposed an approach to minimize the total cost per inventory cycle. Hardik N. Soni (2013) [8] formulated a mathematical model and then some useful theoretical results have been derived to characterize the optimal solutions for non-zero and zero ending inventory system. Chih-Te Yang (2014) [9] developed an inventory model under a stock-dependent demand rate and stock-dependent holding cost rate with relaxed terminal conditions to determine the optimal order quantity and the ending inventory level such that the total profit per unit time was maximized for the retailer. Kun-Shan Wua et al. (2006) [10] considered a problem of determining the optimal replenishment policy for non-instantaneous deteriorating items with stock-dependent demand. Chun-Tao Chang et al. (2010) [11] amended Wu et al.'s model by changing the objective to maximizing the total profit and set a maximum inventory level in the model to reflect the facts that most retail outlets have limited shelf space. They relaxed the restriction of the zero ending inventory when shortages were not desirable then established the theoretical results and provided an algorithm to find the optimal solution. Chia-Hsien Su (2012) [12] established a two-echelon inventory model to encourage sales the supplier offers trade credit to the retailer. And the decision variables include: replenishment cycle time, the time taken to run out of stock and the number of lots delivered from the 
supplier to the retailer. Parviz Fattahi et al. (2015) [13] proposed a bi-objective multi-product (r, Q) inventory model in which the inventory level is reviewed continuously. The aim of them is to find the optimal value for both order quantity and reorder point through minimizing the total cost and maximizing the service level of the proposed model simultaneously. K. Inderfurth and G. P. Kiesmüller (2015) [14] proposed two novel approaches to derive optimal and near-optimal numerical values for the critical stock level, minimizing the average holding and backorder cost for a given inflation factor. Han Zhu et al. (2015) [15] considered a single-item periodic-review stochastic inventory system with both minimum order quantity (MOQ) and batch ordering requirements. Ali Cheaitou et al. (2014) [16] proposed a single-product, stochastic, two-period inventory control model, which combines demand forecast updating with the flexibility of two supply sources. Gitae Kim et al. (2015) [17] presented a multi-period news vendor model, and the problem is formulated as a multi-stage stochastic programming model with integer recourse decisions to optimize the total logistic cost for perishable products. Cinthia Pérez and Joseph Geunes (2014) [18] analyzed an inventory replenishment model with two transportation modes so as to reduce the inventory cost.

According to the literature review, we can get that previous scholars have made some research on inventory management and replenishment strategy of the supermarket chains fresh agricultural products, but only focused on individual supermarkets to find the optimal strategy to achieve a certain type of supermarket inventory management and not apply the transverse replenishment strategy to the inventory management. In this paper, it will regard all sub supermarket stores of the supermarket chains as a system. Then, the transverse replenishment strategy will be applied. Not only to solve each of the stores of fresh agricultural products inventory costs and restocking fee how to achieve the optimal, more emphasis on system overall inventory replenishment strategy optimal, and system of replenishment goods optimal strategy to prior to a single store replenishment goods optimal strategy. Through the regulation and supervision of the store inventory, supermarket chains can effectively reduce the overall cost of fresh agricultural products inventory, improve the profit margins of fresh agricultural products.

\section{Situation Analysis of the Replenishment and Deployment of Supermarket Chains Fresh Agricultural Produce}

To complete this study, large supermarket chains in Beijing was investigated. There are several main survey questions: the order cycle of fresh agricultural products, the order amount of fresh agricultural products, whether it will be out of stock or the surplus goods and so on.

\subsection{Findings}

The survey found that the order cycle of most fresh agricultural products in supermarket chains is once a day. Resupply fresh agricultural products every morning before the open of stores, and with supply schedule. Only the order amount of fresh agricultural products of the sub supermarket chains store surveyed reach $1-20,000$ Yuan. The suppliers of this supermarket chains are the surrounding two distribution centers. The supermarkets form strategic partnerships with them, fixed to supply the appropriate amount of fresh agricultural products to the supermarket chains every day.

The maximum time of daily sales of fresh agricultural products is from nine to ten o'clock in the morning and from five to nine five o'clock in the afternoon. The reason for this phenomenon is that in the morning, the elderly choose to in part to purchase the relatively high-quality fresh agricultural products considering the advantage and the freshness of it, but in the afternoon, it is time of coming off duty of white-collar workers, so that the fresh agricultural products is more sales in the period of time.

In addition, the order types of fresh agricultural products in supermarket chains will change with the seasons. The types of fresh agricultural products are with seasonal fruits and vegetables, supplemented by a small amount of off-season fruits and vegetables. Usually there will be shortage or surplus situation are these off-season fruits and vegetables.

\subsection{Traditional Solutions for Shortage or Surplus of Fresh Agricultural Products Problems}

Supermarket chains in different geographical reasons, traffic conditions, household type, consumption levels and the size of their size, is leading to the different selling degrees of fresh agricultural products. Some supermarket owns surplus of fresh agricultural products because there is less people to buy fresh agricultural products, some 
supermarkets occur shortage phenomenon because there are more people to buy fresh agricultural products. Fresh agricultural products are easy to spoilage due to its own characteristics, which is a special class of commodities with shortest ordered period in supermarkets. And because the order cycle of fresh agricultural products category is very short, so when there is shortage phenomenon, just waiting for the replenishment by suppliers or self-built distribution center. But such an approach will result in the loss of profit which could be got, and this will reduce the supermarket customer service levels, result in the decrease of customer satisfaction, the reduction of source, and decline the purchase price. In addition, in order to obtain a certain income, the supermarket chains will give the discount when sales the surplus of fresh agricultural products. However, this approach would result in the loss of supermarket chains profits. And if using such methods, in the remaining amount of supermarket fresh produce more, it would not sale all the surplus of fresh agricultural products at the time of the arrival of the next order cycle. Also, when new merchandise is reached, the surplus of fresh agricultural products is easy to become the backlog commodities that cannot be sold, resulting in greater losses.

\section{Feasibility Analysis of Transverse Replenishment Method}

It is a relatively new approach that transverse replenishment thinking applied to the replenishment of fresh agricultural products in supermarket chains. That conduct transverse replenishment of fresh agricultural products between supermarket stores is when there is shortage, or surplus of supermarket stores, appropriate to transport the surplus fresh agricultural products of the supermarket stores to the shortage fresh agricultural products of the supermarket stores in some period of time, thus timely and effectively solving the shortage, or surplus problems of fresh agricultural products of the supermarket stores. Through the transverse replenishment, the advantages that it owns can be summary as follows:

Fresh agricultural products between the supermarket stores will be allocated optimally to improve the overall profits after adding transverse replenishment. And this can reduce profits loss of the shortage situation when the supermarket stores take no notice of the shortage situation, and when the supermarket stores treat the surplus fresh agricultural products at discount prices, this can reduce profits loss of the surplus situation.

All sub supermarket stores of the supermarket chains are regard as a system. That means that when there is shortage or surplus of fresh agricultural products of some supermarket stores, then the shortage of the part of supermarket stores do not represent the shortage of the supermarket chains system, the surplus stock of the part of supermarket stores can not represent the surplus of the supermarket chains system. From the perspective of system, the transverse replenishment strategy can optimize the fresh agricultural products inventory.

There is not a problem that unstable partnership occurs between the sub supermarket chains stores since all sub supermarket chains stores are unified managed by the headquarters.

The distance between them should be taken into consideration when the sub supermarket stores transfer fresh agricultural products from a store to another store. Therefore, transfer goods between stores can improve arrival rate. For the supermarket stores out of stock, the transport costs of transferring fresh agricultural products from other supermarket stores are much lower than the supply center. And for small quantities of fresh agricultural products out of stock, transfer fresh agricultural products from other sub-goods supermarket stores will be more convenient. This can help short the replenishment time and improve customer service levels to a certain extent.

The replenishment price of fresh agricultural products is relatively stable, which can be controlled between the purchase price of the distribution center and the selling price of the supermarket stores. And it can be priced by headquarters to reduce the replenishment costs.

From what has been described and discussed above, the transverse replenishment has more advantages. It can be used in supermarkets fresh agricultural products replenishment, but it needs to combine the use of traditional replenishment strategy so as to play their strengths. Because it cannot exclude the situation that inventory shortage or excess of the entire supermarket chains will occur. Therefore, the transverse replenishment of fresh agricultural products between stores needs to combine traditional way to provide services of the supermarket chains.

\section{Transverse Replenishment Inventory Model and Transportation Model Design}

\subsection{Problem Descriptions}

Due to the certain small demand of fresh agricultural products not up to the required amount of the distribution center, the distribution center is not to carry out the distribution or because the distribution center is relatively far from the supermarket stores, resulting in the shortage situation of fresh agricultural products. When some su- 
permarket stores predict the demand of fresh agricultural products, there is large deviation, which results in excessive accumulation of fresh agricultural products. For the cases above, the transverse replenishment will be applied to supermarket stores, which will be more rational to use the resources fresh agricultural products to further reduce costs and losses.

Transverse replenishment of the supermarket chains fresh agricultural products aims to make the optimal allocation of reasonable inventory of the supermarket fresh agricultural products, to minimize the total costs, and to get the entire optimal system. To solve the issue of the replenishment of the fresh agricultural products between the supermarket chains stores, the transverse replenishment inventory model can be established. Firstly, to make the whole system to the minimum inventory costs, meanwhile, to make optimal replenishment strategies of all stores to the lowest cost. And, finally, the total cost of the entire system will be the lowest.

\subsection{Model Assumptions}

We assume that the order lead time of fresh agricultural products is same and unchanged. All supermarket stores apply $(s, S)$ storage strategy. The demand of fresh agricultural products is independent and is in keeping with poisson distributions. The operational status of each supermarket store is same. When the stock fresh agricultural products are less than $s$, then restocking to $S$. In the case of each supermarket stores appear out of fresh agricultural products, only when the existing inventory below the safety stock quantity, there is replenishment applications from the supermarket stores, which stock stores is greater than the safety stock. The symbols and meanings involved in the model are as follows: Each supermarket chains store is represented as $i, j$, and $N$ is the total number. The fresh agricultural products inventory of the supermarket chains system is represented as $S_{0}$, the fresh agricultural products stocks of store $i$ is represented as $S_{i}$. The ordering cost of fresh agricultural products of each supermarket chains stores is represented as $C_{r}$. The unit time fee of fresh agricultural products of each supermarket chains stores is represented as $C_{h}$. The Shortage Costs of fresh agricultural products of each supermarket chains stores is represented as $C_{l}$. The lateral transportation costs of fresh agricultural products of each supermarket chains stores is represented as $C_{i j}$, the average transportation cost of the supermarket chains stores is represented as $C_{i}^{*}$. The probability of supermarket store $i$ meeting the demand of fresh agricultural products with its own stocks is represented as $\alpha_{i}$. The probability of supermarket store $i$ meeting the demand of fresh agricultural products rely on transverse replenishment is represented as $\beta_{i}$. The probability that the fresh agricultural products of supermarket store $i$ out of stock is represented as $\lambda_{i}$. Because only when the fresh agricultural products of entire system is out of stock, then the fresh agricultural products of each supermarket store may is out of stock, therefore, the probability of the shortage of system fresh agricultural products: $\lambda=\lambda_{i}$. The expectation customer service levels of the supermarket chains system is represented as $\varepsilon$. The demand of fresh agricultural products of unit time of supermarket stores $i$ is represented as $D_{i}$; the demand of fresh agricultural products of system is represented as $D_{0}$; the average demand of each supermarket store is represented as $\mu_{i}$; the replenishment quantities from store $i$ to stores $j$ is represented as $D_{i j}$. The replenishment lead time of fresh agricultural products of each supermarket chains stores is represented as $L_{i}$. It is the time that from the issue replenishment orders to the commodity storage.

\subsection{Model Establishment}

The total inventory costs include order costs, storage costs, lateral transportation costs, the shortage loss costs.

For the order costs $C_{R}$ : the order cost of fresh agricultural products can be represented a product by a single order costs and the total number of orders.

$$
C_{R}=\sum_{i=1}^{N} C_{r} \times \frac{\mu_{i}}{S_{i}-S_{i}}
$$

In the formula, $S_{i}-s_{i}$ represents the actual shortage amount of each time, $\frac{\mu_{i}}{S_{i}-s_{i}}$ represents the total number of orders.

For the storage costs $C_{H}$ : the order cost of unit time of fresh agricultural products can be represented a product by the unit storage cost and the Average inventory quantities.

Because the model is based on the premise allowing out of stock, so the average inventory quantities do not include the demand quantities in the period of lead time. The average inventory quantities and the storage costs 
can be got as follows:

$$
\begin{gathered}
\frac{S_{i}+S_{i}}{2}-\mu_{i} L_{i} \\
C_{H}=\sum_{i=1}^{N} C_{h} \times\left(\frac{S_{i}+s_{i}}{2}-\mu_{i} L_{i}\right)
\end{gathered}
$$

Lateral transportation costs $C_{T}$ : the transverse transportation costs is related with the average transportation costs, the average demand rate of fresh agricultural products and the probability of meeting the demand of fresh agricultural products through transverse transportation.

Throughout the supermarket chains system, there are three cases about the stock demand of fresh agricultural products: 1) the fresh agricultural products of stores can be met through the original stock, then the probability is $\alpha_{i}$; 2) the fresh agricultural products of stores can be met through lateral transportation, the probability is $\beta_{i}$; 3) the entire supermarket system is out of stock, the fresh agricultural products cannot be met, then the probability is $\lambda_{i}$. And, $\alpha_{i}+\beta_{i}+\lambda_{i}=1$.

According to independent demand inventory model, in the period of order lead time, the demand of store $i$ is $D_{i} L_{i}$, then:

$$
\alpha_{i}=P\left(D_{i} L_{i} \leq s_{i}\right)
$$

If the system is out of stock, it does not meet the conditions of transverse replenishment. Then, the store $i$ is out of stock in the period of optimal ordering, while other stores $j$ is in the lead time or in the period of order cycle. And the demand is always greater than the actual stocks of stores. Then, the probability is as follows:

$$
\left\{\begin{array}{l}
\lambda_{i}=P\left(D_{i} T_{i}>S_{i}\right) \times \prod_{j=1}^{N} P\left[D_{j}\left(T_{j}-L_{j}\right)>\left(S_{j}-S_{j}\right)\right] \\
T_{i}=\sqrt{\frac{2 C_{r}}{\mu_{i} C_{h}}}(j \neq i)
\end{array}\right.
$$

Average demand of the supermarket store $i$ mentioned in the parameter setting is $\mu_{i}$, but the actual average demand need to be further refined. Some of which are transported from other supermarket stores laterally, and they did not affect the overall system inventory, therefore, they need to be removed. After the transverse replenishment among other stores, there are still unresolved demand, and the demand in this part needs to be calculated in the store $i$. The actual average demand of the store $i$ fresh agricultural products is derived as follows.

$$
\overline{\mu_{i}}=\left\{\mu_{i}+\sum_{\substack{j=1 \\ j \neq i}}^{N} \mu_{j} \beta_{j}\left[1-\left(1-\partial_{1}\right)\left(1-\alpha_{2}\right)\left(1-\partial_{3}\right) \cdots\left(1-\alpha_{N}\right)\right]\right\}\left(1-\beta_{i}\right)
$$

The lateral transportation costs of the whole supermarket chains system can be obtained from the above equation as follows:

$$
C_{T}=\sum_{i=1}^{N} C_{i}^{*} \times \overline{\mu_{i}} \times \beta_{i}
$$

The shortage loss costs of the whole supermarket chains system is as follows:

$$
C_{L}=\sum_{i=1}^{N} C_{l} \times \overline{\mu_{i}} \times \lambda_{i}
$$

In summary, the inventory total cost model of fresh agricultural products of the supermarket chains system is as follows:

$$
\min C\left(s_{i}, S_{i}\right)=C_{R}+C_{H}+C_{T}+C_{L}=\sum_{i=1}^{N} C_{r} \times \frac{\overline{\mu_{i}}}{S_{i}-s_{i}}+\sum_{i=1}^{N} C_{h} \times\left(\frac{S_{i}+s_{i}}{2}-\overline{\mu_{i}} L_{i}\right)+\sum_{i=1}^{N} C_{i}^{*} \times \overline{\mu_{i}} \times \beta_{i}+\sum_{i=1}^{N} C_{l} \times \overline{\mu_{i}} \times \lambda_{i}
$$

s.t. $\alpha_{i}+\beta_{i}>\varepsilon$

If there is no lateral transportation between supermarket store, the model becomes the follows: 


$$
\min C\left(S_{i}, s_{i}\right)=C_{R}+C_{H}+C_{L}=\sum_{i=1}^{N} C_{r} \times \frac{\overline{\mu_{i}}}{S_{i}-s_{i}}+\sum_{i=1}^{N} C_{h} \times\left(\frac{S_{i}+s_{i}}{2}-\overline{\mu_{i}} L_{i}\right)+\sum_{i=1}^{N} C_{l} \times \overline{\mu_{i}} \times\left(1-\alpha_{i}\right)
$$

s.t. $\alpha_{i} \leq \varepsilon$

Assume that eventually all fresh agricultural products of the supermarket chains system is distributed to all the sub stores of the supermarket chains system, the model will be the supply and demand balance transport model. m represents the stores that has Surplus, referred to as $A_{1}, A_{2}, A_{3}, \ldots, \ldots A m$. $n$ represents the stores that has shortage, denoted by $B_{1}, B_{2}, B_{3}, \ldots, \ldots B n$. The quantities of surplus is recorded as $a_{1}, a_{2}, a_{3}, \ldots, \ldots, \ldots a m$ The quantities of shortage is recorded as $b_{1}, b_{2}, b_{3}, \ldots, \ldots, \ldots b n . x_{i j}$ is the transporting capacity of the supermarket chains which is transported from store $A_{i}$ owning surplus to store $B_{j}$ that has shortage $(i=1,2,3, \ldots, \ldots m$, $j=1,2,3, \ldots, \ldots n) . C_{i j}$ represents the unit transportation costs from store $A_{i}$ to store $B_{j} d_{i j}$ is the distance from store $A_{i}$ to store $B_{j}$, but it will be affected by traffic in the actual transportation process. If it is considered only in distance or unit transportation cost. There will be inaccurate to the distribution program of the whole system. And the traffic situation the day is not the same in each time. $\rho_{i j}$ represents traffic situation coefficients from store $A_{i}$ to store $B_{j} . \rho_{i j}$ is only in $0-1$. The more it is closer to 1 , the better the traffic situation it is. On the contrary, it is worse. $\theta_{i j}$ represents the quality factor of fresh agricultural products from store $A_{i}$ to store $B_{j}$. $\theta_{i j}$ is only in $0-1$. The more it is closer to 1 , the better the quality factor it is. On the contrary, if it is closer to 0 , it is worse.

When there is shortage of store $i$, the store $i$ need to make replenishment application to other stores that owning more fresh agricultural products. And, when store $i$ has the surplus of fresh agricultural products goods stores, the surplus that has excess safety stock, needs to be transported to the stores is out of fresh agricultural products. Then, the transverse replenishment transportation model is established on the basis of the traditional transportation model as follows:

$$
\begin{gathered}
\min Z=\sum_{i=1}^{m} \sum_{j=1}^{n} \frac{c_{i j} d_{i j} x_{i j}}{\rho_{i j} \theta_{i j}} \\
\text { s.t. }\left\{\begin{array}{l}
\sum_{j=1}^{n} x_{i j}=a_{i} \\
\sum_{i=1}^{m} x_{i j}=b_{j} \\
\sum_{i j}^{m} a_{i}-\sum_{j=1}^{n} b_{j}=\sum_{i=1}^{N} \overline{\mu_{i}}=0 \\
0<\rho_{i j} \leq 1 \\
0<\theta_{i j} \leq 1 \\
i=1,2, \cdots m \\
j=1,2, \cdots, n
\end{array}\right.
\end{gathered}
$$

\section{Application Example One}

\subsection{Background Description}

A supermarket is a national supermarket chains and is the large-scale retail enterprises. There are a total of seven regional chain store, these stores are replenish by the same fresh agricultural products distribution center. In recent years, in order to increase traffic, improve the market competitiveness of industry peers, the supermarket chains increase a significant operating proportion of fresh agricultural products in supermarkets stores, and regard the fresh agricultural products as highlights and features.

Since the distribution center is relatively far from the supermarket stores, or due to the certain small demand of fresh agricultural products not up to the required amount of the distribution center, the distribution center is not to carry out the distribution, resulting in the shortage situation of fresh agricultural products. Because when some supermarket stores predict the demand of fresh agricultural products, there is large deviation, which results 
in excessive accumulation of fresh agricultural products. And the fresh agricultural products cannot be sold due to the rot, the profit margins of the fresh agricultural products will be reduced. For the cases above, the transverse replenishment will be applied to the supermarket, which will be used to solve the shortage and the surplus problems of fresh agricultural products.

\subsection{Data Calculation}

The operational status of the seven chain stores is same. The demand of fresh agricultural products is independent and is in keeping with poisson distributions. The order lead time of fresh agricultural products is same and unchanged. All supermarket stores apply $(s, S)$ storage strategy.

Related data are as follows:

1) The $S_{i}, s_{i}$ of each supermarket store, the average transportation cost: $C_{i}^{*}$ is as shown in the Table 1.

2) The single ordering cost: $C_{r}=1000$, the inventory holding costs of a single piece of fresh produce of unit time: $C_{h}=5$, the shortage loss costs of a single piece of fresh agricultural products: $C_{l}=20$.

3) The demand of fresh produce stores varies every day. Criteria to the demand of a month, the average daily demand $\mu_{i}$ of the store is as shown in Table 1 .

The above data are into the formula (1) and formula (2), then the order costs, storage costs can be obtained under the conditions of not allowing transverse replenishment. Figure 1 shows the calculation of order costs by using MATLIB. Figure 2 shows the calculation of storage costs by using MATLIB.

Table 1. Data of each sub supermarket stores.

\begin{tabular}{cccccccc}
\hline Number of stores & 1 & 2 & 3 & 4 & 5 & 6 & 7 \\
\hline$S_{i}$ (piece) & 550 & 580 & 480 & 460 & 520 & 500 & 540 \\
$S_{i}$ (piece) & 50 & 60 & 55 & 40 & 50 & 55 & 45 \\
$C_{i}^{*}$ (yuan/piece) & 3 & 4 & 3 & 5 & 5 & 4 & 3 \\
$L_{i}$ (day) & 2 & 1.5 & 2.5 & 2 & 1.5 & 1.5 & 2 \\
(piece) & 55 & 80 & 60 & 70 & 60 & 50 & 65 \\
\hline
\end{tabular}

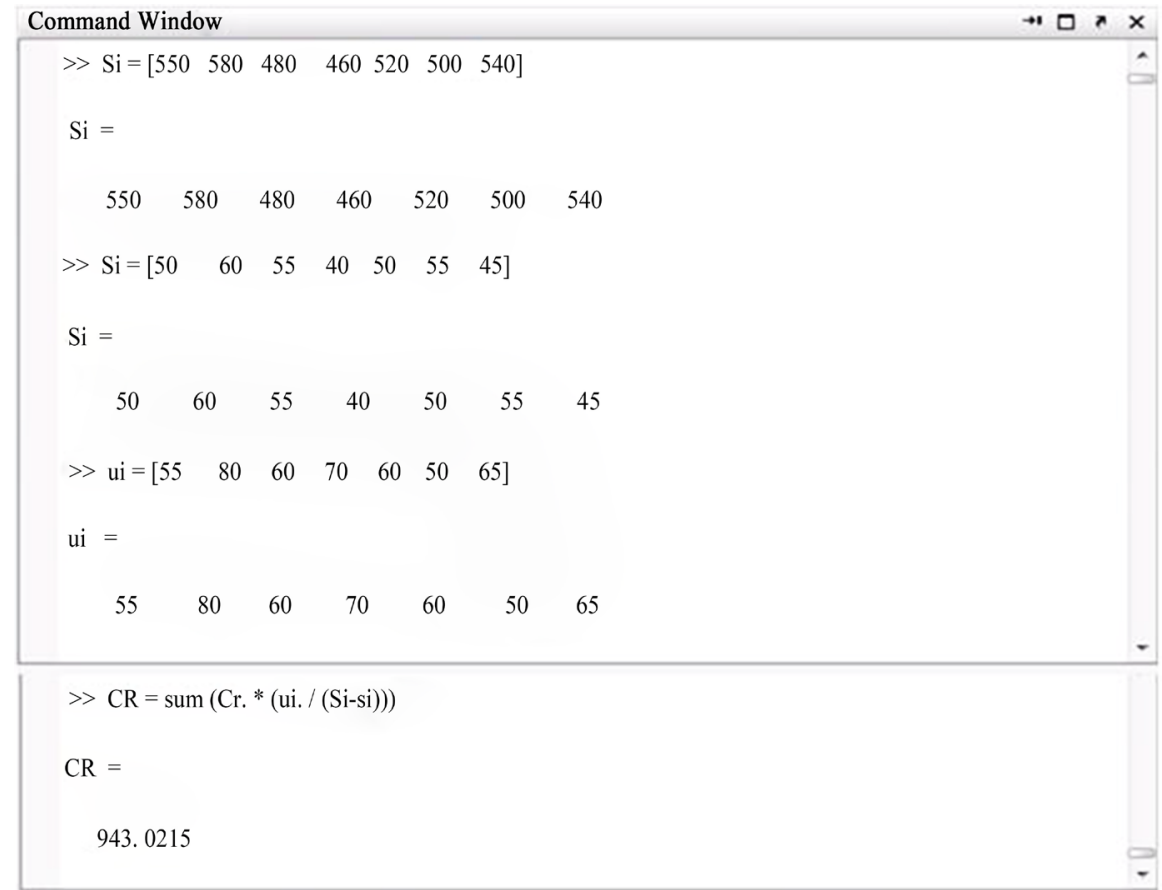

Figure 1. Using matlab to calculate order costs. 


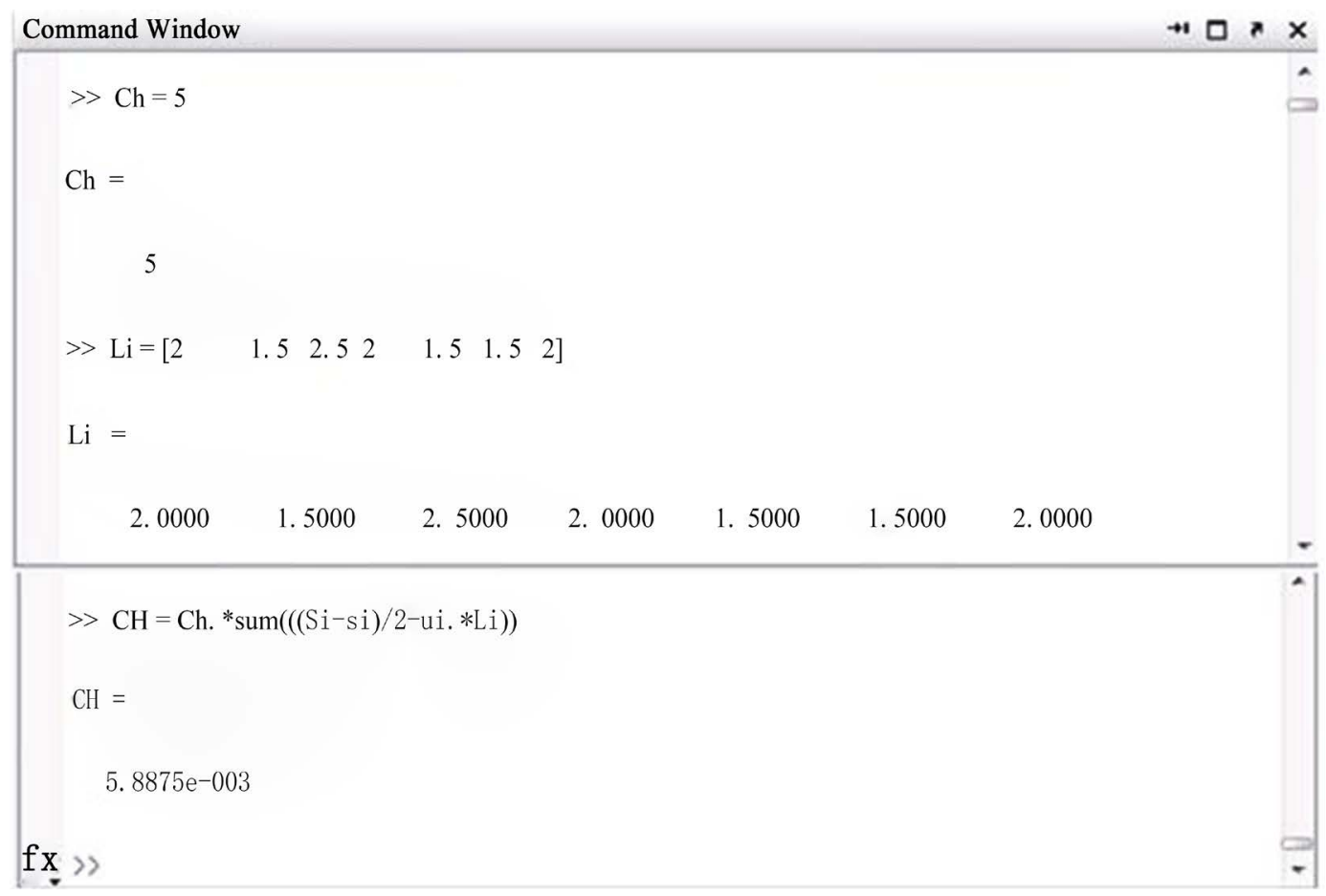

Figure 2. Using matlab to calculate storage costs.

$$
\begin{gathered}
C_{R}=\sum_{i=1}^{N} C_{r} \times \frac{\mu_{i}}{S_{i}-S_{i}}=943.0215 \\
C_{H}=\sum_{i=1}^{N} C_{h} \times\left(\frac{S_{i}+S_{i}}{2}-\mu_{i} L_{i}\right)=5887.5
\end{gathered}
$$

4) The demand of fresh agricultural products is in keeping with poisson distributions: $D_{i} \sim P\left(\sigma_{i}\right)$;

$$
\sigma_{i}=\{30,45,25,24,38,40,26\}, \quad i=1,2,3,4,5,6,7 \text {. }
$$

The fresh agricultural products of stores can be met through the original stock, and the probability is $\alpha$ i. According to the Equation (3) and the probability formula of poisson distributions, the $\alpha_{i}=P\left(D_{i} \leq \frac{s_{i}}{L_{i}}\right)$ can be got. And the The results are shown in Table 2.

When the supermarket chains system is out of stock, it does not meet the conditions of transverse replenishment. Then, supermarket stores at this time needs to place an order to suppliers or distribution center, the rate of shortage is $\lambda_{i}, \beta_{i}$. According to Equation (4) and the formula $\alpha_{i}+\beta_{i}+\lambda_{i}=1$, the results obtained are shown in Table 3.

5) Derive the probability of the supermarket stores using its own inventory to directly meet demand or the probability of the supermarket stores meet demand through replenishment indirectly. According to the formula 5 , the stores actual average demand rate can be got.

$$
\begin{aligned}
\overline{\mu_{1}}= & \{55+[(80 \times 0.4614)+(60 \times 0.4558)+(70 \times 0.4971)+(60 \times 0.5441)+(50 \times 0.4586)+(65 \times 0.5129)] \\
& \times(1-0.7916 \times 0.7445 \times 0.6825 \times 0.7574 \times 0.7635 \times 0.7037 \times 0.7483)\} \times 0.4401=96.8 \\
\overline{\mu_{2}}= & \{80+[(55 \times 0.5599)+(60 \times 0.4558)+(70 \times 0.4971)+(60 \times 0.5441)+(50 \times 0.4586)+(65 \times 0.5129)] \\
& \times(1-0.7916 \times 0.7445 \times 0.6825 \times 0.7574 \times 0.7635 \times 0.7037 \times 0.7483)\} \times 0.5386=129.0
\end{aligned}
$$


Table 2. Probability data of store’s own inventory to meet demand.

\begin{tabular}{|c|c|c|c|c|c|c|c|}
\hline Number of stores & 1 & 2 & 3 & 4 & 5 & 6 & 7 \\
\hline$\sigma_{i}$ & 30 & 45 & 25 & 24 & 38 & 40 & 26 \\
\hline$S_{i} / L_{i}$ & 25 & 40 & 22 & 20 & 33.33 & 36.67 & 22.5 \\
\hline$\alpha_{i}$ & 0.2084 & 0.2555 & 0.3175 & 0.2426 & 0.2365 & 0.2963 & 0.2517 \\
\hline
\end{tabular}

Table 3. Probability data of indirect replenishment to meet demand.

\begin{tabular}{ccccccccc}
\hline Number of stores & 1 & 2 & 3 & 4 & 5 & 6 & 7 \\
\hline$\lambda_{i}$ & 0.2317 & 0.2831 & 0.2267 & 0.2603 & 0.2194 & 0.2451 & 0.2354 \\
$\beta_{i}$ & 0.5599 & 0.4614 & 0.4558 & 0.4971 & 0.5441 & 0.4586 & 0.5129 \\
\hline
\end{tabular}

6) The above data are into the formula (6) and formula (7), then the lateral transportation costs, the shortage loss costs can be obtained.

$$
\begin{aligned}
& C_{T}=\sum_{i=1}^{N} C_{i}^{*} \times \overline{\mu_{i}} \times \beta_{i}=1525.20616 \\
& C_{L}=\sum_{i=1}^{N} C_{l} \times \overline{\mu_{i}} \times \lambda_{i}=3905.72842
\end{aligned}
$$

7) The order costs, storage costs can be obtained under the conditions of allowing transverse replenishment.

$$
\begin{gathered}
C_{R}=\sum_{i=1}^{N} C_{r} \times \frac{\overline{\mu_{i}}}{S_{i}-S_{i}}=1718.63374 \\
C_{H}=\sum_{i=1}^{N} C_{h} \times\left(\frac{S_{i}+s_{i}}{2}-\overline{\mu_{i}} L_{i}\right)=2542.58535
\end{gathered}
$$

8) According to the inventory cost model, the total cost of inventory can be obtained under the conditions of allowing transverse replenishment.

$$
\begin{aligned}
& \min C\left(s_{i}, S_{i}\right)=C_{R}+C_{H}+C_{T}+C_{L} \\
& =\sum_{i=1}^{N} C_{r} \times \frac{\overline{\mu_{i}}}{S_{i}-S_{i}}+\sum_{i=1}^{N} C_{h}\left(\frac{S_{i}+s_{i}}{2}-\overline{\mu_{i}} L_{i}\right)+\sum_{i=1}^{N} C_{i}^{*} \times \overline{\mu_{i}} \times \beta_{i}+\sum_{i=1}^{N} C_{l} \times \overline{\mu_{i}} \times \lambda_{i}=9692.15213
\end{aligned}
$$

9) When the supermarket chains system does not meet the needs of fresh agricultural products, supermarket stores at this time needs to place an order to suppliers or distribution center. Then, there will be no lateral transportation costs, and the the total cost of inventory is as follows.

$$
\begin{aligned}
& \min C\left(s_{i}, S_{i}\right)=C_{R}+C_{H}+C_{L} \\
& =\sum_{i=1}^{N} C_{r} \times \frac{\mu_{i}}{S_{i}-s_{i}}+\sum_{i=1}^{N} C_{h} \times\left(\frac{S_{i}+s_{i}}{2}-\mu_{i} L_{i}\right)+\sum_{i=1}^{N} C_{l} \times \mu_{i} \times\left(1-\alpha_{i}\right) \\
& =943.0125+5887.5+11809.8512=18640.36372
\end{aligned}
$$

\subsection{Results Analysis}

With regard to the two inventory costs of allowing the transverse replenishment and not allowing the transverse replenishment, it can be got that the total inventory cost of allowing the transverse replenishment is lower than the total inventory cost of not allowing the transverse replenishment. When the supermarket adopt the transverse replenishment, even though the loss caused by shortages is much lower than ordering directly to the distribution centers, even though it needs bear the cost of transporting in the lateral transportation, and even though the storage costs are slightly higher than the cost of the replenishment adopted by distribution center or supplier, there but is a relatively small impact on the total cost of inventory. Therefore, the supermarket adopt the transverse 
replenishment can make the total inventory costs of the entire supermarket chains system's more lower.

\section{Application Example Two}

\subsection{Background Description}

Because the transverse replenishment inventory model obtains the total inventory cost of allowing the transverse replenishment is lower than the total inventory cost of not allowing the transverse replenishment. So, it can be provided for the supermarket chains to reduce the loss of fresh agricultural products. After the analysis and calculation of inventory cost model, we can transport the fresh agricultural products from stores owning surplus to store owning shortage. Then, the best transportation plan should be designed in order to transport the fresh agricultural products with the lowest transportation costs.

\subsection{Data Calculation}

Table 4 shows the unit transportation cost data. Table 5 shows the distance data of stores. Table 6 shows the traffic coefficient merits. Table 7 shows the quality coefficient table of fresh agricultural products. Related data of all stores of a supermarket chains are as follows:

According to the data, the transverse replenishment transportation model can be established.

Table 4. Stores distance data (unit: kilometers).

\begin{tabular}{cccccc}
\hline$C_{i j}$ & $B_{1}$ & $B_{2}$ & $B_{3}$ & $B_{4}$ & Surplus quantity \\
\hline$A_{1}$ & 2 & 3 & 5 & 3 & 600 \\
$A_{2}$ & 3 & 4 & 6 & 3 & 800 \\
$A_{3}$ & 2 & 5 & 4 & 1 & 1200 \\
shortage quantity & 300 & 500 & 1000 & 800 & \\
\hline
\end{tabular}

Table 5. Unit shipment data.

\begin{tabular}{cccccc}
\hline$d_{i j}$ & $B_{1}$ & $B_{2}$ & $B_{3}$ & $B_{4}$ & Surplus quantity \\
\hline$A_{1}$ & 5 & 10 & 15 & 12 & 600 \\
$A_{2}$ & 8 & 10 & 7 & 9 & 800 \\
$A_{3}$ & 6 & 5 & 10 & 8 & 1200 \\
Shortage quantity & 300 & 500 & 1000 & 800 & \\
\hline
\end{tabular}

Table 6. Traffic coefficient merits.

\begin{tabular}{ccccc}
\hline$\rho_{i j}$ & $B_{1}$ & $B_{2}$ & $B_{3}$ & $B_{4}$ \\
\hline$A_{1}$ & 0.2 & 0.5 & 0.7 & 0.6 \\
$A_{2}$ & 0.4 & 0.3 & 0.8 & 0.5 \\
$A_{3}$ & 0.6 & 0.8 & 0.3 & 0.7 \\
\hline
\end{tabular}

Table 7. Quality coefficient table of fresh agricultural products

\begin{tabular}{ccccc}
\hline$\square \theta_{i j}$ & $B_{1}$ & $B_{2}$ & $B_{3}$ & $B_{4}$ \\
\hline$A_{1}$ & 0.2 & 0.5 & 0.7 & 0.6 \\
$A_{2}$ & 0.4 & 0.3 & 0.8 & 0.5 \\
$A_{3}$ & 0.6 & 0.8 & 0.3 & 0.7 \\
\hline
\end{tabular}




$$
\begin{gathered}
\min Z=\sum_{i=1}^{3} \sum_{j=1}^{4} \frac{c_{i j} d_{i j} x_{i j}}{\rho_{i j} \theta_{i j}} \\
\text { s.t. }\left\{\begin{array}{l}
\sum_{j=1}^{4} x_{i j}=a_{i} \\
\sum_{i=1}^{3} x_{i j}=b_{j} \\
\sum_{i=1}^{3} a_{i}-\sum_{j=1}^{4} b_{j}=\sum_{i=1}^{4} \overline{\mu_{i}}=0 \\
x_{i j} \geq 0 \\
0<\rho_{i j} \leq 1 \\
0<\theta_{i j} \leq 1 \\
i=1,2,3 \\
j=1,2,3,4
\end{array}\right.
\end{gathered}
$$

According to the traditional method of solving the transport model, we first need to calculate the underlying table, which is listed as follows. Table 8 shows the underlying table of table-manipulation method.

For the accuracy of the calculation, Vogel method is used here to find the initial solution. Table 9 shows the initial solution of the transportation program.

Use the potential algorithm to distinguish the optimal initial solution, and the optimal transportation plan is obtained.

$$
\begin{aligned}
& A_{1} \Rightarrow B_{1}(300), A_{1} \Rightarrow B_{4}(300) ; \\
& A_{2} \Rightarrow B_{3}(800) ; \\
& A_{3} \Rightarrow B_{2}(500), A_{3} \Rightarrow B_{3}(200), A_{3} \Rightarrow B_{4}(500) .
\end{aligned}
$$

\subsection{Results Analysis}

From the above we can see that he transverse replenishment transport model above get the optimal dispatching scheme between stores, that means when we transport the fresh agricultural products from the surplus supermarket stores to the shortages supermarket stores, this strategy can be used to reduce the transportation costs.

\section{Table 8. The underlying table of table-manipulation method.}

\begin{tabular}{cccccc}
\hline$\frac{c_{i j} d_{i j}}{\rho_{i j} \theta_{i j}}$ & $B_{1}$ & $B_{2}$ & $B_{3}$ & $B_{4}$ & Surplus quantity \\
\hline$A_{1}$ & 71 & 150 & 357 & 120 & 600 \\
$A_{2}$ & 100 & 267 & 66 & 60 & 800 \\
$A_{3}$ & 40 & 45 & 222 & 23 & 1200 \\
Shortage quantity & 300 & 500 & 1000 & 800 & \\
\hline
\end{tabular}

Table 9. Initial solution of the transportation program.

\begin{tabular}{cccccc}
\hline & $B_{1}$ & $B_{2}$ & $B_{3}$ & $B_{4}$ & 0 \\
$A_{1}$ & 0 & 400 & 0 & 0 \\
$A_{2}$ & 250 & 0 & 350 & 0 \\
$A_{3}$ & 50 & 50 & 0 & 200 \\
Shortage quantity & 300 & 500 & 1000 & 800 \\
\hline
\end{tabular}




\section{Conclusion}

The goal of the research is to minimize the total inventory cost of the overall system in the process of replenishment, to maximize the overall system profits. All the sub-supermarket stores of the supermarket chains are regarded as a whole system to be researched in this paper. This paper applies the transverse replenishment thinking to the replenishment of the supermarket chains, provides the solution to deal with the shortage or surplus of supermarket chains fresh agricultural products, and the shortcomings issue of traditional replenishment methods, and provides the solution to deal with the shortcomings issue of only considering the local interest of the traditional replenishment thinking. By the establishment of the transverse replenishment inventory model and the analysis of the actual examples, it can be concluded that the total inventory cost of allowing the transverse replenishment is lower than the total inventory cost of not allowing the transverse replenishment. Through the establishment of transverse replenishment transportation model, the optimal dispatching scheme between the surplus supermarket and the shortages supermarket is given. This paper can provide a reference for the supermarket chains to deal with the shortage or surplus of fresh agricultural products. And, This will help the supermarket chains to improve sales margins of agricultural products, to reduce the total inventory costs of the whole the supermarket chains system, and to improve the customer service levels.

\section{References}

[1] Wang, W.X. and Han, Y. (2006) An Inventory Management Model for Deteriorating Items with Shortage under a Multi-Echelon Supply Chain. Logistics Sci-Tech Technology, 29, 96-99.

[2] Shui, W.B., He, M. and He, M.W. (2012) A Multi-Product Location-Inventory Model Based on Coordinated Replenishment Policy. Logistics Sci-Tech Technology, 29, 134-139.

[3] Kouki, C., Jemaï, Z. and Minner, S. (2015) A Lost Sales (r,Q) Inventory Control Model for Perishables with Fixed Lifetime and Lead Time. International Journal of Production Economics, 168, 143-157. http://dx.doi.org/10.1016/j.ijpe.2015.06.010

[4] Qin, Y.Y., Wang, J.J. and Wei, C.M. (2014) Joint Pricing and Inventory Control for Fresh Produce and Foods with Quality and Physical Quantity Deteriorating Simultaneously. International Journal of Production Economics, 152, 4248. http://dx.doi.org/10.1016/j.ijpe.2014.01.005

[5] Sarkar, B.and Sarkar, S. (2013) An Improved Inventory Model with Partial Backlogging, Time Varying Deterioration and Stock-Dependent Demand. Economic Modelling, 30, 924-932. http://dx.doi.org/10.1016/j.econmod.2012.09.049

[6] Lee, Y.-P. and Dye, C.-Y. (2012) An Inventory Model for Deteriorating Items under Stock-Dependent Demand and Controllable Deterioration Rate. Computers \& Industrial Engineering, 63, 474-482. http://dx.doi.org/10.1016/j.cie.2012.04.006

[7] Sicilia, J., González-De-la-Rosa, M., Febles-Acosta, J. and Alcaide-López-de-Pablo, D. (2014) An Inventory Model for Deteriorating Items with Shortages and Time-Varying Demand. International Journal of Production Economics, 155, 155-162.

[8] Soni, H.N. (2013) Optimal Replenishment Policies for Non-Instantaneous Deteriorating Items with Price and Stock Sensitive Demand under Permissible Delay in Payment. International Journal of Production Economics, 146, 259-268. http://dx.doi.org/10.1016/j.ijpe.2013.07.006

[9] Yang, C.-T. (2014) An Inventory Model with Both Stock-Dependent Demand Rate and Stock-Dependent Holding Cost Rate. International Journal of Production Economics, 155, 214-221. http://dx.doi.org/10.1016/j.ijpe.2014.01.016

[10] Wu, K.-S., Ouyang, L.-Y. and Yang, C.-T. (2006) An Optimal Replenishment Policy for Non-Instantaneous Deteriorating Items with Stock-Dependent Demand and Partial Backlogging. International Journal of Production Economics, 101, 369-384. http://dx.doi.org/10.1016/j.ijpe.2005.01.010

[11] Chang, C.-T., Teng, J.-T. and Goyal, S.K. (2010) Optimal Replenishment Policies for Non-Instantaneous Deteriorating Items with Stock-Dependent Demand. International Journal of Production Economics, 123, 62-68. http://dx.doi.org/10.1016/j.ijpe.2009.06.042

[12] Su, C.-H. (2012) Optimal Replenishment Policy for an Integrated Inventory System with Defective Items and Allowable Shortage under Trade Credit. International Journal of Production Economics, 139, 247-256. http://dx.doi.org/10.1016/j.ijpe.2012.05.001

[13] Fattahi, P., Hajipour, V. and Nobari, A. (2015) A Bi-Objective Continuous Review Inventory Control Model: ParetoBased Meta-Heuristic Algorithms. Applied Soft Computing, 32, 211-223. http://dx.doi.org/10.1016/j.asoc.2015.02.044

[14] Inderfurth, K. and Kiesmüller, G.P. (2015) Exact and Heuristic Linear-Inflation Policies for an Inventory Model with Random Yield and Arbitrary Lead Times. European Journal of Operational Research, 245, 109-120. 
http://dx.doi.org/10.1016/.ejor.2015.03.006

[15] Zhu, H., Liu, X. and Chen, Y. (Frank) (2015) Effective Inventory Control Policies with a Minimum Order Quantity and Batch Ordering. International Journal of Production Economics, 168, 21-30. http://dx.doi.org/10.1016/j.ijpe.2015.06.008

[16] Cheaitou, A., van Delft, C., Jemai, Z. and Dallery, Y. (2014) Optimal Policy Structure Characterization for a Two-Period Dual-Sourcing Inventory Control Model with Forecast Updating. International Journal of Production Economics, 157, 238-249. http://dx.doi.org/10.1016/j.ijpe.2014.07.028

[17] Kim, G., Wu, K. and Huang, E. (2015) Optimal Inventory Control in a Multi-Period Newsvendor Problem with NonStationary Demand. Advanced Engineering Informatics, 29, 139-145. http://dx.doi.org/10.1016/j.aei.2014.12.002

[18] Pérez, C. and Geunes, J. (2014) A (Q, R) inventory Replenishment Model with Two Delivery Modes. European Journal of Operational Research, 237, 528-545. http://dx.doi.org/10.1016/j.ejor.2014.02.049

\section{Submit or recommend next manuscript to SCIRP and we will provide best service for you:}

Accepting pre-submission inquiries through Email, Facebook, LinkedIn, Twitter, etc.

A wide selection of journals (inclusive of 9 subjects, more than 200 journals)

Providing 24-hour high-quality service

User-friendly online submission system

Fair and swift peer-review system

Efficient typesetting and proofreading procedure

Display of the result of downloads and visits, as well as the number of cited articles

Maximum dissemination of your research work

Submit your manuscript at: http://papersubmission.scirp.org/ 